\title{
Nicotine Withdrawal
}

National Cancer Institute

\section{Source}

National Cancer Institute. Nicotine Withdrawal. NCI Thesaurus. Code C7698.

A condition which occurs following suspension of nicotine use. Clinical features may include nicotine craving, irritability, anxiety, depression and increased appetite. The onset of symptoms may be rapid with severity proportional to length and amount of nicotine use. Unsuccessful management of symptoms may prompt a return to nicotine use. 